\title{
PUEBLOS ORIGINARIOS Y POLÍTICAS DE RECONOCIMIENTO EN ARGENTINA
}

\author{
Héctor Hugo TRINCHERO $\left({ }^{1}\right)$
}

\begin{abstract}
Resumen
Las disposiciones jurídico-políticos que tienen incluso rango constitucional y garantizan el reconocimiento de los pueblos originarios argentinos cargan con el peso del sistema de representaciones que históricamente se ha construido en torno a los modos de representación de la identidad nacional.

Una de las claves para comprender esta situación es la forma de ocupación del espacio rural, tanto el modelo histórico, como el reciente con la constante expansión de la frontera agraria para la producción de granos, especialmente soja, vinculada al mercado mundial. El objetivo de este artículo es dar cuenta de la situación actual de los pueblos originarios en la Argentina a través de un análisis conceptual y estadístico, y aportar a una caracterización del conflicto de representaciones e intereses que tiende a agudizarse día a día.
\end{abstract}

Palabras clave: pueblos indígenas - política de reconocimiento- identidad étnicaterritorio-reproducción económico /social

\begin{abstract}
The legal and political regulations, even included in the Constitution, which guarantee the recognition of Argentine indigenous peoples carry the weight of the system of representations historically built around the different ways of national identity representations.

This situation is evidenced in the historical occupation of rural space as well as the current occupation with the constant expansion of the agricultural area devoted to grain production for the international market, specially soy.

This work is aimed at examining the current situation of Argentine indigenous peoples through a theoretical and statistical analysis, and a characterization of the conflict of representations and interests tending to get worse every day.

Keywords: indigenous people-recognition policy - ethnic identity - territory economic social reproduction
\end{abstract}

\section{Résumé}

Les dispositions juridico-politiques qui ont même une valeur constitutionnelle et qui garantissent la reconnaissance des peuples originaires argentins sont fort chargées $d u$ système de représentations qui, historiquement, s' est construit autour des modes de représentations de l' identité nationale.

Une des clés pour comprendre cette situation est la manière dont est occupé l' espace rural, tantôt le modèle historique comme le récent, avec l' expansion constante de la frontière agricole pour la production de grains, en espécial, le soja, en rapport avec le marché mondial.

L' objectif de cet article est de rendre compte de la situation actuelle des peuples originaires en Argentine à travers d' une analyse conceptuelle et statistique, et d' apporter

1 Profesor Titular del Departamento de Ciencias Antropológicas. Facultad de Filosofía y Letras de la Universidad de Buenos Aires. Investigador principal del CONICET, Argentina. 
une caractérisation du conflit de représentations et d' intérêts qui tend à se faire plus aigu jour après jour.

Mots-clé: population indigène - politique de reconnaissance -identité éthnique -territoire-reproduction économique /social

\section{Los pueblos originarios en las narrativas de la nación}

Cuando los especialistas se remiten a la caracterización de la población indígena Argentina presentan una serie de resguardos previsibles frente a una problemática reconocidamente compleja, máxime teniendo en consideración ciertos rasgos prototípicos de la cultura hegemónica nacional. Es que, históricamente, desde el punto de vista de la denominada "historia oficial", la República Argentina ha sido definida políticamente y caracterizada sociológica y antropológicamente como una nación "sin indios", o como lo expresara el reconocido sociólogo brasileño Darcy Ribeiro un país de pueblos transplantados. En el mismo sentido, una nación cuyo modelo imaginado de representaciones responde o se configura demográfica y culturalmente por pueblos trasplantados "que descienden de los barcos" es una nación que no reconoce como constitutiva de sus dispositivos de identidad a los pueblos originarios. Esta situación incluso ha intentado validarse desde una política censal: No hay indicaciones censales a lo largo de la historia sobre la pertenencia a identidades aborígenes de grupos poblacionales $\left({ }^{2}\right)$.

Sin embargo estos discursos políticos y académicos que también tienen su impronta en la literatura, el arte pictórico, el folletín, la historieta, la museografía, etc. apuntan a desconocer el proceso histórico de conquista y apropiación territorial por parte del estado y agentes privados dominantes. Semejante desconocimiento del proceso histórico viene siendo señalado en distintas oportunidades por historiadores, sociólogos y antropólogos. Así, una parte significativa de los investigadores y académicos que se han especializado en el tema sostienen que la relación de los pueblos originarios con los conquistadores españoles, primero, y con el estado nacional, a partir de mediados del siglo XIX, ha estado definida por el sojuzgamiento militar, el etnocidio, la expulsión o subsunción al sistema de expansión agrícola-ganadero y agroindustrial de la fuerza de trabajo sobreviviente, de acuerdo al modelo de desarrollo económico preponderante en cada región. Todo ello en sintonía con el intento de aculturación mediante distintos programas estatales y de evangelización y cuyas consecuencias se observan en la des-estructuración de las modalidades prototípicas de organización social, política y económica, la expropiación territorial y la degradación cuando no la depredación de los recursos naturales que configuraron su base de sustentación económica y sociocultural (Trinchero, 1987, Trinchero; Piccinini \& Gordillo,1992; Balazote \& Radovich, 1992; Vázquez, 2000; Hidalgo \& Tamagno, 1992; Bechis, 1992; Golluscio, 2002).

Este relativo consenso requiere incluso avanzar en su caracterización historiográfica. En este sentido es posible sostener una situación particular si lo comparamos con el resto de América Latina: durante el período de conquista española y por el particular escenario que ocupaban los territorios del Río de la Plata en la economía colonial, una gran parte del espacio que era habitado por poblaciones indígenas no fue efectivamente ocupado por los conquistadores ni sus descendientes, lo que configuró una situación de "pactos y acuerdos" entre los colonizadores españoles y las distintas "naciones" indígenas con tal

2 En realidad, el Primer Censo Nacional de Población realizado en 1869 durante la presidencia de Sarmiento había arrojado sólo para el Territorio Nacional del Chaco un total de 45.291 indígenas. Sin embargo ningún informe de la época tenía en cuenta los datos sobre la población indígena. Mucho menos aún informes y documentos posteriores ya que los censos siguientes omitieron toda mención sobre población indígena en Argentina, es decir, no existía como categoría censal. 
de preservar el principal objetivo económico de los primeros en los territorios del Cono Sur: rutas alternativas a la salida de los metales preciosos. Esto implicaba, más allá incluso de intervenciones punitivas (cuando los conquistadores suponían una ruptura de determinado pacto), una cierta política de reconocimiento que incluso se profundizó durante el período independentista. Sin embargo hacia mediados del siglo XIX y con el proceso denominado de "formación del Estado Nacional" y en consonancia con la incorporación del hinterland pampeano al proceso de producción de alimentos para el mercado mundial, tiene lugar un profundo viraje en la política hacia los pueblos originarios y el mismo consiste lisa y llanamente en su negación como ciudadanos del nuevo Estado, dando lugar a una política genocida mediante las eufemísticamente denominadas "campañas al desierto" $\left(^{3}\right)$.

Es indiscutible el hecho de que con la reafirmación de la democracia en el país, la reforma constitucional de 1994 se ha planteado un retorno a la política de reconocimiento de las poblaciones indígenas. Así, por ejemplo, dicha reforma constitucional define en su artículo 75 inc. 17 como atribución del Congreso de la Nación, reconocer la preexistencia étnica y cultural de los pueblos indígenas, garantizando el respeto a su identidad y el derecho a una educación bilingüe e intercultural. Asimismo, reconoce la personería jurídica de las comunidades y la posesión y propiedad comunitaria de las tierras que tradicionalmente ocupan, y regula la entrega de otras aptas y suficientes para su desarrollo humano. Garantiza también su participación en la gestión referida a sus recursos naturales y a los demás intereses que los afecten.

Por su parte, el inciso 19 define también como atribución del Congreso dictar leyes que protejan la identidad y pluralidad cultural. El inciso 22 adopta, con rango constitucional, el Pacto Internacional de los Derechos Económicos, Sociales y Culturales, y la Convención Internacional sobre la eliminación de todas las formas de discriminación racial. Por otra parte, la ley 24071 adopta el Convenio 169 de la OIT, habiéndose depositado el instrumento de ratificación en las instancias correspondientes durante julio del 2000. En conjunto, todos estos cuerpos legales constituyen un avance en relación con el anterior marco jurídico de la Constitución de 1853 que preveía como atribución del Congreso "conservar el trato pacífico con los indios y promover su conversión al catolicismo(sic)".

Estos avances en las políticas de reconocimiento están en consonancia con la incorporación de derechos indígenas en reformas constitucionales latinoamericanas posteriormente a los regímenes dictatoriales en la región, caso Brasil, Paraguay y Bolivia. No obstante, lo anterior no sólo es parte del proceso democratizador sino que también debe contextualizarse en el marco de las reformas del Estado en el Cono Sur durante la década de los 90 's, orientadas a la desregulación y retirada de la injerencia estatal en la provisión de servicios y coberturas sociales básicas. Así, estas políticas han operado en un sentido inverso al reconocimiento de los derechos indígenas, pues contribuyeron a la exclusión y pauperización de las poblaciones más vulnerables y entre ellas los pueblos originarios.

Más allá, entonces, de la vigencia de las normativas mencionadas, en los hechos se observa una escasa implementación de los mandatos constitucionales, lo que implica una gran distancia entre las disposiciones de la letra jurídica y la producción de políticas

3 Tal como lo planteo en distintos textos, la Constitución Argentina de 1853 reconoce los pactos preexistentes sólo en aquellas ocasiones que involucran a los caudillos provinciales, pero con los pueblos originarios y las "naciones" indígenas no hay pacto alguno que valga. A partir de allí comienza el proceso de invisibilización jurídico-política de la población indígena y un modelo de modernidad excluyente y justificadora de políticas de exterminio. (Trinchero, 1992, 2000, 2006. Bartolomé, 2003). 
concretas. Por ejemplo, muy poco se ha avanzado en una de las principales reivindicaciones de los pueblos indígenas, como es la de "asegurar la posesión y propiedad comunitaria de las tierras que tradicionalmente ocupan", según sanciona la constitución reformada. Son muy escasos los casos de "regulación dominial" y menos aún aquellos casos en los que se reconoce la propiedad/posesión comunitaria. Los programas de regularización dominial proceden con excesiva lentitud. En los pocos casos instrumentados, lejos se está aún de regular la "entrega de otras tierras aptas y suficientes para el desarrollo humano" en aquellas situaciones donde las tierras ocupadas no sean aptas, ya que debe tenerse en cuenta no únicamente el acceso al recurso (tierra) sino a la calidad del mismo y en cantidad suficiente que garantice la implementación de determinado proyecto productivo. Poco o nada se ha realizado, al menos como esfuerzo de política pública, para generar estudios sobre modelos productivos y tipos de EAP (Emprendimiento o unidad de producción agropecuaria, según el Censo Agropecuario Nacional) que tome en cuenta las modalidades de producción y reproducción económica y social de las unidades domésticas y comunidades indígenas.

Ahora bien, independientemente de la debilidad de las políticas públicas hacia las poblaciones indígenas del país, existe un proceso económico estructural en el cual la expansión de la frontera agraria y la concentración económica rural ha avanzado incluso sobre las tierras tradicionalmente ocupadas por pueblos originarios y reconocidas constitucionalmente, lo que constituye un verdadero obstáculo, muy difícil de superar en las actuales condiciones económicas. Es decir, existe una evidente contradicción entre el conjunto de normativas jurídico-políticas tendientes a garantizar determinados derechos hacia los pueblos originarios y la estructura agraria del país que se articula en torno a un modelo agro exportador y de concentración fundiaria y empresarial. No por casualidad Argentina es uno de los pocos países latinoamericanos en cuya constitución o en todo caso en cuyo organigrama estatal, no se encuentra institucionalizado un plan o programa de reforma agraria. $\left({ }^{4}\right)$

La hipótesis de trabajo que intento sostener es que los problemas que son posibles de detectar con relación al reconocimiento del derecho a la identidad se relacionan con semejante contradicción señalada. En este sentido, existen datos y evidencias claras en la mayoría de los pleitos en los que intervienen instancias judiciales y administrativas en los cuales por más que la normativa estipula el criterio de autoafirmación como base para definir la identidad indígena, por lo general no se aplica este criterio, siendo el estado y sus instituciones quienes pretenden juzgar quién es o debería ser indígena.

Tampoco debe perderse de vista que los pueblos originarios de la República Argentina se encuentran hoy en las regiones donde existen los mayores índices de pobreza y de indigencia. Se hallan por tanto entre los grupos poblacionales con mayores dificultades de acceso a servicios esenciales de salud, vivienda, educación, como así también a los recursos, particularmente a la tierra y al trabajo.

\section{Sobre definiciones y clasificaciones}

Partiendo de lo señalado anteriormente, podremos observar también que no sólo el Estado se enfrenta a aquella contradicción entre el derecho a la identidad de los pueblos originarios, sus implicancias, posibilidades y limitaciones. El campo académico e investigativo especializado en la temática en no pocas oportunidades también queda desorientado frente a la cuestión. Así, mientras se afirma el criterio de auto

4 Únicamente los movimientos sociales indígenas y campesinos de base y algunos intelectuales ligados o no a dichas organizaciones plantean como reivindicación la necesidad de una reforma agraria en Argentina. 
reconocimiento, se escriben innumerables páginas acerca de la definición de indio, indígena, grupo étnico, comunidad, pueblo, nación indígena, etc. $\left({ }^{5}\right)$

Con el objetivo de problematizar también la cuestión, y en aras de situarnos frente a propuestas concretas, se discuten algunas líneas conceptuales que trasciendan la caracterización fenomenológica de los sujetos involucrados, es decir partiendo del criterio que ni al Estado ni a los científicos les corresponde definir quien es o no es indígena, a riesgo de involucrarse con políticas inconducentes y anticonstitucionales.

\section{Definir y clasificar}

Es posible señalar que en las últimas décadas, y en consonancia con las políticas de reconocimiento, la Antropología Argentina ha comenzado a utilizar crecientemente como concepto de auto reconocimiento para la pertenencia a cualquier otro grupo étnico.

Para la adopción de dicha categoría, un importante aporte reconocido por la antropología nativa lo constituyó la obra de Fredrik Barth sobre los grupos étnicos y sus fronteras (escrita en 1969 y traducida al castellano en 1976), ya que se impuso una apertura hacia miradas no escencialistas del tema. Sus conceptos significaron un intento de ruptura respecto de los abordajes "culturalistas" dominantes hasta los años '40 y '50. Aquellas perspectivas, definían "lo indígena" sobre la base de rasgos culturales "estáticos" e identificaban "una raza con una cultura" (Hidalgo, 1992). A continuación enumeramos los criterios sobre los que tales abordajes construían la categoría de indígena y describimos las limitaciones inherentes a cada una de estas definiciones:

1) Criterio biológico: El uso de criterios biológicos está asociado estrechamente con la concepción del indígena en términos raciales, lo cual resulta obsoleto dada la amplitud de la miscegenación ocurrida entre las diferentes poblaciones. Se apela en estos casos a la "pureza de raza" sin considerar la historia como factor inherente a la conformación de poblaciones basadas en el intercambio, y sin considerar la cultura como espacio supra biológico, propio del campo social, ambiente a partir del cual nuestra especie se constituye en subjetividades particulares.

2) Criterio de enumeración de rasgos culturales: utilizado para concebir de manera "estanca" a los grupos étnicos. Son atributos que se deben cumplir para pertenecer a la categoría. Aquí se reemplaza la idea de "pureza de raza", por la de "esencia cultural", ya que tampoco se contempla un proceso de conformación histórico fundado en una relación social desigual. Tampoco se considera el cambio, como si las culturas permanecieran estáticas.

3) Criterio lingüístico: es utilizado como indicador para las estimaciones censales en países como México en el cual siguen preservándose las lenguas indígenas. Sin embargo el uso de las lenguas aborígenes tampoco resulta un indicador suficiente. El ejemplo más extremo de la falta de correspondencia entre la población hablante de un idioma indígena y el grupo social denominado "indio" lo podemos encontrar en el vecino país de Paraguay, dónde el $80 \%$ de los habitantes hablan el Guaraní y sólo el 2,6\% de la población total es considerada indígena (Bonfil Batalla; 1992: 25-26). Es posible coincidir con Bonfil Batalla (1992) en cuanto a la inconsistencia del criterio lingüístico como indicador de la pertenencia a un pueblo indígena, en especial cuando, tal como encontramos en el caso mapuche, les ha sido impuesta otra lengua.

5 Por supuesto no estoy objetando el debate en torno a la definición de esas categorías sino intento relativizar su eficacia cuando hablamos de determinada población indígena en particular, ya que sus diacríticos pueden ser tomados como referencia por instituciones estatales o privadas deconstruyendo la noción misma de auto adscripción. 
4) Criterio etnocéntrico o definición por la negativa: este criterio consiste en definir a las poblaciones a partir de la negación de rasgos y atributos generados por la sociedad occidental. Son sociedades sin Estado, sin economía, sin escritura, sin religión, etc. En este caso se los define a partir de la carencia, de aquello que no poseen culturalmente. Este planteo remite a cierto etnocentrismo ya que se supone que se trata de poblaciones en un estadio evolutivo inferior al occidental por lo que aún no desarrollaron las instituciones propias de la modernidad.

En contraste con estas acepciones, y desechando la ecuación de una "raza = cultura", propia de los enfoques culturalistas, Barth enfatizó: “(...) el hecho que los grupos étnicos son categorías de adscripción e identificación que son utilizadas por los actores mismos y tienen la característica de organizar la interacción entre los individuos" (1976:10-11). Por esto a partir de la influencia de la obra de Barth, los antropólogos van a resaltar el carácter relacional de las identidades sociales $\left({ }^{6}\right)$.

Con relación al primer aspecto, la auto-percepción (esto es, el auto reconocimiento como indígenas) constituye una variable central ya que implica la representación subjetiva de valores que sirven a la perpetuación de identidades, en este caso la pertenencia a los diferentes pueblos indígenas.

El otro elemento que a partir de los 70' los antropólogos van a considerar como central es el carácter relacional de las identidades. La premisa respecto a las identidades como producto de un sistema de relaciones nos permite comprender el concepto mismo de "indio" o "indígena". En este sentido a principios de los '70, Bonfil Batalla va a advertir que la categoría supraétnica de "indio" constituía una forma de designar al colonizado dentro de una estructura colonial que incluía al colonizador. De acuerdo a lo planteado por este autor, la definición de "indio" no se basa en el análisis de las particularidades propias de cada grupo ya que el espectro de variaciones es tan amplio que ninguna definición a partir de sus características internas puede incorporarlas a todas. Pensemos que con tal categoría de "indio" se designa en el momento de la conquista desde pueblos cazadores - recolectores del Amazonas hasta las denominadas altas culturas estatales de Meso América y los Andes.

Entonces, la categoría de indígena no denota ningún contenido específico de los grupos que abarca, sino una relación en el sistema social global del que los mismos forman parte. De hecho, el "indio" como categoría genérica e indiferenciada que abarca la totalidad de pueblos originarios, solo tiene sentido en el contexto del orden colonial, cuya característica es identificar a los pueblos colonizados en oposición a los colonizadores (Bonfil Batalla, 1992: 25-26).

Por esto las definiciones que atienden a rasgos "estáticos" no consideran el lugar de las poblaciones indígenas en la totalidad del contexto social y el carácter históricamente determinado de la relación entre los pueblos originarios y el Estado-nación. No son herramientas válidas para el análisis en la medida en que impiden comprender los procesos a través de los cuales se reproducen y resignifican las identidades étnicas - al igual que las restantes identidades sociales -. Por esto también, las definiciones o lecturas efectuadas por tales abordajes sólo pueden definir a los grupos indígenas "por lo que no

6 Esto es igualmente válido para una multiplicidad de antropólogos que van a criticar a Barth por no considerar lo suficiente las interacciones entre grupos étnicos en el marco de un sistema social determinado. No obstante, estos especialistas, van a rescatar del mismo y enfatizar el carácter interactivo y procesual de estas identidades (Cardoso de Oliveira, 1992; Bartolomé, 1997; Díaz Polanco, 1995; Bechis, 1992; Trinchero, 2000; Vázquez; 2000; Balazote, 1994 y Radovich, 1992). 
son" en lugar de atender a los complejos procesos que intervienen en las relaciones interétnicas en el devenir histórico.

En la Argentina se considera oficialmente como criterio válido para la definición de lo indígena este concepto dominante en la Antropología de la auto-percepción. Por ello es que en el censo efectuado en el año 2001 se entrevistó a la población indígena residente en el medio rural y en el urbano, utilizando como criterio el auto reconocimiento como forma de análisis de la población indígena. $\left({ }^{7}\right)$

\section{Población Indígena Estimada y Censada.}

Para una evaluación cuantitativa de la población indígena y su distribución resulta interesante distinguir entre estimaciones y estudios censales, ya que unas y otras contienen implícitamente apreciaciones subjetivas que es necesario considerar a la hora del análisis.

Según una estimación efectuada en el año 1988, en América Latina existirían 40 millones de indígenas distribuidos de forma sumamente heterogénea (Iturralde, 1995:116). Esto se debe a la proporción variable en que intervino la población originaria en lo que hoy conforma cada estado-nación, así como a las condiciones concretas de la dominación colonial (Bonfil Batalla, 1991:24). El 90\% de la población originaria corresponde a Meso América (México, Centroamérica y Panamá) y Los Andes (norte de Chile y Bolivia, Colombia, Ecuador, Perú y Venezuela). Las tres regiones restantes (Amazonía, Cono Sur y Caribe) concentran el restante $10 \%$ de la población originaria del sub-continente.

Argentina es uno de los países con menor proporción de indígenas en su conformación nacional (entre 1\% y 2\%). En otros casos, la población originaria es mayoritaria -tal es el caso de Bolivia (71\%) y Guatemala $(66 \%)$-, o bien representa una proporción muy significativa, como el caso de Perú (47\%) o Ecuador (43\%). Sobre un total de 32 países que integran el continente americano, Argentina ocupa el puesto 28 en cuanto a la incidencia relativa de sus poblaciones originarias en la conformación nacional (Iturralde, 1995:117-118). Sin embargo y sobre todo para el caso argentino, resulta muy difícil tomar fielmente los datos existentes como representativo, según veremos.

Aún así, y aunque esta cifra no exprese fehacientemente la presencia de dichos pueblos en la población argentina, la misma constituye un indicador estadístico que al menos implica su reconocimiento. Puede considerarse incluso que esta cifra sub-representa dicha presencia. Independientemente de ello, la misma indica que como porcentaje de la población total los indígenas en Argentina son numéricamente más representativos respecto a la población total que, por ejemplo, a la población total de Brasil. Sin embargo a nadie se le ocurriría plantear que en Brasil no hay indígenas, como sí sucede en reiteradas ocasiones en Argentina. Esto significa que mas allá de las estadísticas existe un hecho histórico que indica que los pueblos originarios -la población indígena- no ha sido reconocida como parte de la formación social, cultural y política de la nación, independientemente que desde hace ya varios años exista una legislación que intente revertir esta situación.

7 Un importante antecedente de medición de la población indígena en la Argentina fue el Censo Nacional Indígena (C.N.I.) realizado durante los años 1966/67, donde los datos dieron cuenta de una población indígena de algo más de 250.000 personas en Argentina, lo que representa algo más del 1\% de los habitantes. En algunos departamentos de las provincias de Río Negro, Neuquén, Chaco y Formosa, pueden llegar a representar el 30 o 40\% de la población total. Sin embargo, es importante destacar que en este censo sólo se tomó a la población que vivía en reservas o en comunidades, excluyendo a quienes habían emigrado a las ciudades o habitaban en forma dispersa en áreas rurales (Radovich y Balazote, 1992:10). 
El último censo poblacional argentino (2001), incluyó por primera vez en tiempos recientes una variable que intentaba registrar la pertenencia indígena de la población censada. A partir de una pregunta sobre la pertenencia y la descendencia de algún pueblo indígena se obtuvo una cifra de población total indígena de 1.117.746, de los cuales 554.127 son varones y 563.619 mujeres. El censo distingue la localización poblacional entre población urbana (agrupamientos con 2000 o más personas), población rural agrupada (menos de 2000 personas) y población rural dispersa.

$\begin{array}{llll}\text { Cuadro No } 1 \text { Población indígena total por sexo según localización } \\ \text { Localización } & \text { Varones } & \text { Mujeres } & \text { Total } \\ \text { Urbana } & 448.597 & 467.408 & 916.005 \\ \text { Rural agrupada } & 30.477 & 29.837 & 60.314 \\ \text { Rural dispersa } & 75.053 & 66.374 & 141.427 \\ \text { Total } & 554.127 & 563.619 & 1.117 .746\end{array}$

Fuente: Censo Nacional de Población, Hogares y Viviendas 2001 Instituto Nacional de Estadística y Censos (INDEC)

Es importante señalar el peso significativo de la población indígena urbana (916.005 sobre un total de 1.117.746) según el criterio de localización seguido por el Censo. Por lo que prácticamente el $82 \%$ de la población indígena se encuentra asentada en ámbitos urbanos.

La cantidad de Hogares que tienen algún miembro que se considera indígena es de 281.959 , es decir prácticamente el 3\% de los hogares totales. Al mismo tiempo el Censo Nacional de Población ubica claramente a la población indígena en un porcentaje mayor que la población general dentro de hogares con necesidades básicas insatisfechas (NBI). Así, 66.187 hogares indígenas se encuentran con sus necesidades básicas insatisfechas, es decir el $23,47 \%$ del total de hogares indígenas, mientras que para el resto de los hogares es del $11,41 \%$. Al igual que la población, la localización de los hogares es en su amplia mayoría urbana (el $85 \%$ en este caso).

Es necesario ser conscientes de los problemas que conlleva el criterio de auto adscripción en la implementación de la pregunta sobre pertenencia y descendencia indígena de las personas y los hogares. Así por ejemplo, si se cruzan los datos numéricos de la población que se reconoce indígena con nacionalidad de origen tenemos un número importante de registros de personas que se reconocen indígenas nacidos en España, Italia, y números menores en muchos otros países del mundo, lo cual es un absurdo. Podría tenerse en cuenta la población inmigrante de países vecinos que se reconoce indígena como el caso de Bolivia, Paraguay, Chile, Brasil, Perú y Uruguay. Independientemente de esto, la sola pregunta del Censo no garantiza un criterio de auto adscripción sobre la categoría indígena ya que dicha pregunta en sí da lugar a distintas interpretaciones (confundiendo muchas veces pertenencia con apoyo a la causa indígena o bien nativo de determinada localidad en su país de origen, etc.)

Es por ello que los datos que, aún con problemas, mejor representan una estimación de la población indígena en Argentina son los de la Encuesta Complementaria de Pueblos Indígenas que analizaré a continuación.

A partir de los datos recabados en el Censo efectuado en el año 2001, el Instituto Nacional de Estadísticas y Censos (INDEC) realizó la Encuesta Complementaria de Pueblos Indígenas dentro del período 2004 - 2005 (ECPI). El objetivo de este trabajo, ha sido cuantificar y caracterizar a la población que se reconoce perteneciente y descendiente de pueblos indígenas. En este estudio, para identificar a la población se respetó la declaración de las personas entrevistadas y se combinaron dos criterios: la auto identificación o auto reconocimiento de la pertenencia a un pueblo indígena y la 
ascendencia indígena en primera generación (INDEC, 2004-2005). En el informe presentado al PSA por parte del equipo del Programa, se mencionaba que: "De acuerdo a los resultados de la ECPI en la Argentina hay 600.329 personas que se reconocen pertenecientes y/o descendientes en primera generación de pueblos indígenas" (2006: 8. Esta evaluación debe también ser revisada a la luz del criterio de autoadscripción propuesto. A continuación, en el Cuadro 2 se presentan los datos agrupados sobre la población indígena clasificada según los dos criterios utilizados.

CUADRO $\mathbf{N}^{\circ}$ 2: Población según Modos de Auto reconocimiento y Ascendencia Indígenas. Total del País. Años 2004 Y 2005

Modos de reconocimiento

Se reconocen pertenecientes a un pueblo indígena $(*)$

Población censada

No se reconoce perteneciente a un pueblo indígena y desciende de 142.966 pueblos indígenas en primera generación

Total

Fuente: INDEC. Encuesta Complementaria de Pueblos Indígenas (ECPI) 2004-2005 Complementaria del Censo Nacional de Población, Hogares y Viviendas 2001.

La población que se reconoce perteneciente a un pueblo indígena está clasificada sobre la base del criterio de auto reconocimiento, independientemente de si tiene ascendencia indígena o no. Pero también en el censo se efectúa la pregunta complementaria que indaga acerca de la descendencia que posee de algún pueblo o nación indígena. El 93,4\% de la población que se reconoce perteneciente a un pueblo indígena desciende de ese pueblo indígena en primera generación por parte de padre o de madre (INDEC, 20042005).

Cuando afirmamos anteriormente que la evaluación realizada en torno a que habría 600.329 pobladores indígenas debe replantearse, es porque aquellos que no se reconocen como pertenecientes a un pueblo indígena, no deben considerarse como parte del universo si es que el criterio seguido es el del auto reconocimiento, independientemente que posean ascendencia indígena en primera generación. Por lo tanto, siguiendo la Encuesta Complementaria como referente para establecer cuál es la población indígena del país, la cifra que corresponde es la de 497.647 pobladores, que incluso habría que depurar ya que hay casos de doble adscripción y representan una cifra cercana al $6 \%$ de los casos.

Al visualizar la pertenencia a los diferentes pueblos indígenas asentados en todas las provincias del país, observamos que los pueblos Mapuche, Kolla, Toba y Wichí, Diaguita/Diaguita Calchaquí en conjunto agrupan más de la mitad de la población relevada.

En el siguiente Cuadro 3 se presenta la población indígena según el pueblo indígena de pertenencia y ascendencia en primera generación.

De acuerdo a los datos aportados por el Cuadro, el pueblo Mapuche es el más numeroso (113.680 integrantes); seguido por el pueblo Kolla -70.505-, toba -69.452-, Wichí -40.036-y Diaguita /DiaguitaCalchaquí con 31.753, sumadas estas cinco etnias representan casi el $54,2 \%$ de la población indígena de nuestro país. Luego siguen en importancia otros pueblos como el guaraní, avá guaraní, tupí guaraní, mocoví, huarpe, comechingón, tehuelche, rankulche, mbyá guaraní, quechua, tonocoté, charrúa, pilagá, chané y aymará, sumando estas etnias el $26,6 \%$ de la población indígena. Tomando en conjunto las primeras 20 etnias en orden de importancia, las mismas conforman más del $80 \%$ de los habitantes indígenas. Seguidamente, 10 grupos poseen menos de 4000 integrantes y más de 500, los que se encuentran discriminados numéricamente. Por 
último, surgen diferentes menciones a etnias con menos de 500 habitantes agrupados bajo la calificación de "otros" (INDEC, 2004-2005.

CUADRO N 3: Población Por Pueblo Indígena. Total Del País.

Años 2004 Y $2005(*)$

Pueblo indígena

Población

Mapuche

113.680

Kolla

70.505

Toba

69.452

Wichí

40.036

Diaguita/diaguita calchaquí

31.753

Guaraní

Ava guaraní

21.807

Tupí guaraní

16.365

Mocoví

Huarpe

Comechingón

10.863

Tehuelche

10.590

Rankulche

10.149

Mbyá guaraní

8.223

Quechua

6.739

Tonocoté

4.779

Charrúa

4.511

Pilagá

4.465

Chané

4.376

Aymara

4.104

Atacama

3.044

Chorote

2.613

Pampa

1.585

Omaguaca

1.553

Lule 854

Querandí 736

Ona 696

Sanavirón $\quad 563$

Chulupí $\quad 553$

Tapiete 524

Subtotal $\quad 497.647$

Otros pueblos declarados 3.864

$(* *)$

Subtotal

501.511

Pueblo no especificado (***) 92.876

Subtotal

594.387

Sin respuesta $\quad 9.371$

Total $\quad 603.758$

Fuente: INDEC (Instituto Nacional de Estadísticas y Censos). Encuesta Complementaria de Pueblos Indígenas (ECPI) 2004-2005 Complementaria del Censo Nacional de Población, Hogares y Viviendas 2001.

Referencias:

(*) La sumatoria de las categorías de este cuadro supera en un $0,6 \%$ el total de población indígena presentado en el Cuadro 1 debido a que la población que no se reconoce perteneciente a ningún pueblo específicamente y tiene ascendencia indígena mixta (sus progenitores pertenecen a distintos pueblos indígenas) está contada en uno y otro pueblo indígena simultáneamente. 
(**) Incluye, entre otros, los casos registrados con las siguientes denominaciones: Abaucán, Abipón, Ansilta, Chaná, Inca, Maimará, Minuán, Ocloya, Olongasta, Pituil, Pular, Shagan, Tape, Tilcara, Tilián y Vilela. No se brindan datos por separado para cada denominación debido a que la escasa cantidad de casos muestrales no permite dar una estimación de cada total con la suficiente precisión.

(***) Incluye los casos en que la respuesta relativa al pueblo indígena de pertenencia y/o ascendencia en primera generación fue "ignorado" u "otro pueblo indígena".

Debe tenerse en cuenta que la ECPI 2004-2005 adolece de similares problemas metodológicos a los del Censo dado el carácter adscriptivo de la pertenencia y es por ello que los organismos tienden a no considerar como relevantes los datos estadísticos sobre población indígena y continúan estimando la población por otras vías.

Las estimaciones que se realizan sobre la población indígena en el país adolecen de criterios homogéneos y confiables. Es por ello que el organismo nacional encargado de entender en la temática el INAI (Instituto Nacional de Asuntos Indígenas) no dispone en su página Web de información al respecto aduciendo que la disponible no es fehaciente

Tanto la escasez como las inconsistencias en las estimaciones sobre población indígena en Argentina son el producto, tal como hemos señalado precedentemente, de una política de invisibilización sistemática desde los inicios mismos de la formación del Estado y la Nación modernos en Argentina. Este no-reconocimiento ha generado paralelamente un desinterés por incorporar la temática a los Censos de Población, entre otras posibilidades. Ello ha dado lugar a estimaciones que se reproducen consensuadamente sin que se hayan analizado críticamente posibles inconsistencias.

\section{Producción, ambiente y territorio}

Si en los aspectos demográficos existe, tal como lo hemos observado, una notable falta de información sustentada. Cuando se trata de la situación productiva y ambiental la cuestión empeora aún más. Para dar cuenta del tema recurro a determinada información y a ciertos análisis antropológico-económicos que he desarrollado en el marco de investigaciones antropológicas en los últimos veinticinco años en el país.

Según nuestro entender, el primer criterio a tener en cuenta es aquel que concibe las prácticas económicas (productivas, de consumo, de circulación de bienes, ambientales, etc.) de las unidades familiares y comunitarias de las poblaciones indígenas insertas en la dinámica económica general. Es recomendable aquí superar el clásico dualismo en la interpretación de la estructura agraria (tradicional vs. moderno) que llevan a caracterizar a la dinámica económica de las comunidades indígenas (y campesinas) en el primer polo de la dicotomía, mientras que el polo "moderno" se encuentra constituido por las agroindustrias, los agro negocios y el proceso general de expansión de la frontera agraria y la concentración económica. La Antropología Económica ha demostrado cómo la economía doméstica es vital, en algunos casos, para el sostenimiento de tasas de remuneración de la fuerza de trabajo rural por debajo de la media nacional (Meillassoux, C. 1984; Balazote, A. 1995; Trinchero, H. 1992, 1995, 2000)

Un segundo criterio que se desprende del anterior es analizar los modelos de subsunción existente entre la economía doméstica rural de las comunidades y pequeños productores familiares (sin entrar aún en una conceptualización específica) y los frentes de expansión agrícola-ganaderos de tipo capitalista en la estructura agraria. Esto implica, nuevamente, dejar de analizar las prácticas productivas y reproductivas de las comunidades indígenas mediante términos "tradicionales" (cazadores-recolectores, pequeños agricultores, etc.) ya que dichas prácticas muy variables adquieren una dimensión específica como parte de la producción y reproducción de la vida. 
El tercer criterio consiste en considerar como parte de la dinámica económica de las comunidades indígenas no únicamente aquellas que remiten a las prácticas más prototípicas. Por ejemplo Mapuches crianceros de ovejas, Wichí, recolectores-cazadores-pescadores, etc., sino incorporar también las nuevas formas de inserción de las comunidades y poblaciones indígenas en proyectos productivos regionales de alto impacto en el mercado de bienes y servicios. Por ejemplo en Turismo, artesanías para el mercado europeo, rentas derivadas del usufructo de territorios. Definitivamente las distintas prácticas productivas con sus respectivas consecuencias e impactos ambientales y territoriales de las comunidades indígenas se encuentran integradas a la dinámica de la economía rural regional.

Si se quieren estimar y analizar los aspectos socio productivos de la población indígena en Argentina como en cualquier parte del mundo es necesario recurrir a aproximaciones, sobre todo, a aquellas que aportan, entre otras, las disciplinas antropológicas económicas y ecológicas con el objeto de dar cuenta de aquellos procesos cambiantes de los sujetos y los grupos productivos que utilizan modalidades de tenencia y/u ocupación precaria de la tierra, modalidades de uso comunitario de los espacios territoriales, o bien prácticas relativamente consuetudinarias de usufructo del ambiente y el territorio, como ser aquellas prácticas de la recolección, la pesca y la caza, entre otras múltiples formas de organización del trabajo familiar y comunitario orientadas antes hacia la reproducción y luego hacia el mercado.

Pero no solo hay que tener en cuenta la dinámica productiva y reproductiva doméstica tanto en el ámbito familiar como en el ámbito comunitario, sino también articular esta mirada con la inserción de las comunidades indígenas en el mercado, ya sea como oferentes y demandantes de bienes, como también como fuerza de trabajo que es empleada en distintos emprendimientos agronómicos y cuyo nivel de empleo y de ingresos es relativamente dependiente de la capacidad de la economía doméstica de sostener la reproducción. Caracterizar correctamente el modo de inserción de las economías indígenas en las estructuras agrarias regionales, permitirá generar algunas orientaciones para la intervención pública en dichos espacios con el objetivo de mejorar las precarias condiciones de vida que hoy padecen.

Siguiendo la bibliografía y estudios especializados, un fenómeno que es necesario caracterizar correctamente es el proceso de expansión de la frontera agropecuaria y la concentración económica en las distintas estructuras rurales. Un proceso que "afectó a los pequeños productores, ocupantes tradicionales de tierras fiscales y privadas, comuneros, pueblos indígenas y aparceros precarios, ha sido la revalorización productiva $\mathrm{y}$ económica de amplias áreas del país, principalmente en el NOA y NEA. Extensas superficies de monte ya degradado por la extracción maderera y la explotación ganadera, son deforestadas para ser incorporadas a la producción agrícola en general, con predominio de soja" (Slutzky, 2008:5).

En un reciente informe de FLACSO, se sostiene que desde la década de los años 70's la producción de soja tuvo un sustantivo crecimiento que se explica por el incremento en la productividad, pero desde inicios de la década de los 90's, ese incremento se basa también en la expansión de la superficie sembrada que pasó de 19,6 millones de hectáreas sembradas con los principales cultivos de exportación durante el año 1993-1994, a 32,6 millones en 2007-2008, Al mismo tiempo se afirma que en un 95\%, este aumento es explicado por la producción de soja (FLACSO; 2009:5). Este fenómeno ha puesto en jaque en las últimas décadas a la dinámica productiva y reproductiva de los pequeños productores rurales campesinos e indígenas, como así también la viabilidad de los ecosistemas en los que dichas poblaciones producen y garantizan sus condiciones de existencia.

Es posible sostener junto con la mayoría de los especialistas en el tema, que las provincias de Tucumán, Salta, Santiago del Estero, Chaco, Formosa y norte de Santa Fe, prácticamente duplican el área agrícola con explotaciones de corte capitalista entre 1988 
y 2002, proceso que continúa en la actualidad. Estas provincias son las que mayor índice de población indígena rural presentan y, además, debe considerarse que la duplicación del área agrícola no se debe precisamente a cultivos y actividades domésticas de los pequeños productores campesinos y de las comunidades indígenas, según veremos más adelante. En otras provincias, como es el caso de Misiones y Corrientes, la revalorización de sus tierras está relacionada con el desarrollo de la foresto industria (...) "Innumerables conflictos se generan ante esta situación en que empresas y propietarios individuales, muchos de ellos con títulos de dudosa legitimidad, intentan por todos los medios incorporar esas tierras 'libres' de ocupantes a las nuevas actividades productivas" (Slutzky, 2008:6).

Dichos conflictos provienen precisamente por el efecto expulsivo de población rural que en algunos casos, especialmente para los grupos indígenas, implican comunidades enteras. Los datos intercensales que dan cuenta de este fenómeno expulsivo de población rural son muy genéricos en sintonía con lo que ya hemos planteado anteriormente. Sin embargo algunos datos, aunque generales, son más que elocuentes con relación al proceso de expansión de la frontera, la concentración económica rural y la expulsión de productores y población en general. Siguiendo el estudio de Chris Van Dam (2008), donde compara los censos de 1988 y 2002, se puede observar que en esos 14 años, desaparecieron alrededor del $25 \%$ de las EAPs. Estas se agregan a las que dejaron de existir entre 1969 y 1988, es decir que, en un poco más de tres décadas (entre 1969 y 2002), desaparecieron casi la misma cantidad de EAPs que las existentes hacia el 2002 en todo el país (333.477). Esto incluye a todo tipo de explotaciones; ya sean propietarios, arrendatarios, aparceros, medieros u ocupantes. Y con la mano de obra, trabajadores y peones rurales, pasó algo parecido: en 2002 había 230.000 personas menos trabajando con relación a 1988, a pesar de que la producción se había incrementado varias veces en ese periodo.

En este contexto y ya en el ámbito nacional, la categoría de "ocupante de hecho" de tierras (es decir sin permiso), ya sea en tierras privadas o en tierras fiscales, ha ido perdiendo representatividad, y en 2002 sólo representan el 1\% de las EAPs. Y eso se explica porque esta forma de tenencia de la tierra, que se concentraba y se sigue concentrando en el NOA, en el NEA y en la Patagonia, se ha ido reducido drásticamente en el periodo intercensal 1988-2002, lo que ha significado la expulsión de muchas familias de "ocupantes", categoría en la que se incluyen la mayoría de las tierras ocupada por comunidades indígenas (Van Dam, 2008:7-8).

Este proceso de expulsión de población, como se dijo, ha impactado fuertemente en la dinámica de las comunidades y pueblos indígenas del país, generando un renovado proceso migratorio hacia las ciudades, cuya característica principal pareciera ser que dichas migraciones se producen hoy en día con mayor intensidad hacia las ciudades intermedias o capitales provinciales y no casi exclusiva y masivamente hacia el Conurbano bonaerense ( Gran Buenos Aires) o Rosario como sucedía en la década de los años 60's y 70's. No existen datos que permitan dar cuenta fehacientemente de este fenómeno con relación a las comunidades indígenas en particular, pero sí es posible analizarlo en función del crecimiento exponencial que presentan las periferias de ciudades como Resistencia, Santa Fe, Tartagal, Neuquén, entre otras.

Ahora bien, independientemente de este fenómeno estructural, las comunidades indígenas rurales intentan resistir, aunque en condiciones desiguales a semejante dinámica expulsiva, reclamando los territorios que son, según una célebre frase "su almacén primitivo de víveres" y al mismo tiempo garantía de su supervivencia como pueblos originarios. Es por ello que la territorialidad es parte constitutiva de las principales demandas de las comunidades y pueblos indígenas rurales. 
Sin embargo y a pesar del reconocimiento constitucional del derecho a la propiedad de la tierra que usufructúan las comunidades indígenas, el proceso de entrega de las mismas es mínimo y no se cuentan, salvo excepciones, datos sistemáticos que reporten sobre el estado de situación de la cuestión.

Para comprender con detenimiento la dinámica productiva de las comunidades, como ya se ha planteado, es necesario incorporar y relacionar el conjunto de actividades que realizan las unidades domésticas y las comunidades, mediante estudios sistemáticos que den cuenta de la complejidad de dichas dinámicas. Para comprender lo que estamos intentando plantear es importante ir brevemente a un par de ejemplos.

En las comunidades Wichí-Chorote del Pilcomayo, las prácticas observables indican actividades típicas del ciclo anual de recursos (Pesca, recolección, caza, agricultura) y también empleo estacional en plantaciones de poroto alubia y otras clases de leguminosas, desmontes, empleos estatales, emprendimientos artesanales. Pero aún la pesca, que puede considerarse como una actividad "tradicional" ha sufrido importantes transformaciones históricas. Si "antiguamente" la pesca se utilizaba exclusivamente para el autoconsumo y el trueque ínter comunitario, hoy camiones procedentes de distintas partes del país e incluso del sur de Bolivia entran a las comunidades para comprar el pescado capturado. Es decir, se pesca para el autoconsumo pero también se pesca para la venta, y la capacidad mayor o menor de pesca y de venta influye directamente sobre el empleo estacional en manos de contratistas que provienen del frente agrícola. Esto es así porque, los pobladores de las comunidades prefieren obtener sus ingresos de la pesca y no de lo que ellos denominan "la poroteada" o "el desmonte" según sea el caso, pues en estos ámbitos los niveles de superexplotación de la mano de obra son altísimos.

Sin embargo y dado que la pesca coincide con la "época flaca", es decir el período de mayor escasez de productos del monte (de la oferta alimentaria ambiental), es el recurso prácticamente excluyente de la economía doméstica en esa época (junio-agosto). Faltando la pesca, pero también el ingreso monetario que produce, los pobladores no tienen otra alternativa que "engancharse" con los contratistas de mano de obra para las plantaciones. Estas prácticas también pueden ser consideradas "ancestrales" ya que el Gran Chaco ha sido desde épocas coloniales un gran reservorio de mano de obra (por ejemplo para trabajos en las minas del Potosí, entre otros) y también que los pobladores indígenas del Chaco centro-occidental (en Argentina) constituyeron la principal fuerza de trabajo en los ingenios azucareros, cuando la expansión de estos, en las primeras décadas del siglo XX en el conocido ramal salto-jujeño (Trinchero, 1995, 2000).

Distinta, en primera instancia, es la economía doméstica de una parte importante de las comunidades Mapuche de norpatagonia (cfr. Balazote, 1994). Allí la mayoría de los pequeños productores indígenas son crianceros de ganado ovino, mediante el cual entran en el mercado lanar y cárnico (este último también para autoconsumo). Sin embargo y más allá de estas particularidades en las prácticas productivas domésticas, también son empleados como peones en las estancias o migran estacionalmente hacia emprendimientos agrarios capitalistas de la región o bien se insertan en actividades del mercado de turismo.

En síntesis, para ambos ejemplos, lo que debe tenerse en cuenta es que las actividades productivas de las poblaciones indígenas rurales combinan de manera específica y particular en cada caso, actividades domésticas con empleo estacional. Es decir son trabajadores rurales cuyos bajos salarios se explican en gran parte porque la reproducción de su fuerza de trabajo en la época de no empleo en los emprendimientos agrícolas capitalistas regionales está garantizada por el esfuerzo productivo doméstico comunitario $\mathrm{y}$, como ese esfuerzo doméstico comunitario está sujeto, como hemos observado, a una serie de constricciones (que es necesario analizar en cada caso) necesitan complementar 
sus ingresos con el empleo estacional o en otros casos con el empleo estatal. Esta dinámica compleja, diferenciada y sobre la cual hacemos aquí una muy somera descripción, puede ser analizada desde los conocimientos que ofrece la Antropología Económica mediante la utilización de matrices insumo-producto que den cuenta del sistema de utilización productiva de los recursos por parte de las unidades domésticas y en su conjunto las comunidades en determinada situación. Según nuestro criterio, ello permitiría diseñar con mayor sistematicidad la estrategia de intervención de proyectos orientados hacia la producción, el ambiente y el territorio.

\section{A modo de síntesis provisional}

Una nación de "pueblos transplantados" construye un imaginario hegemónico en el que no tienen cabida los "pueblos originarios". Es por ello que las recientes políticas de reconocimiento hacia la población indígena nativa se enfrentan a esta concreta historicidad. Aún más, puede decirse que el discurso historiográfico ha tendido, incluso en sus variopintas manifestaciones, a remitir la cuestión indígena a la situación colonial, negando la historia específica de los pueblos originarios en el desarrollo del capitalismo nacional. Es que las campañas de exterminio indígena producidas por el ejército argentino como gesta fundacional tuvieron también el objetivo del disciplinamiento social de los pueblos sobrevivientes, que en semejantes condiciones, configuraron la mano de obra principal del capitalismo agroforestal y azucarero en el norte del país.

El mas reciente proceso de expansión de la frontera agraria capitalista en Argentina genera una dinámica expulsiva de las poblaciones originarias con asentamiento rural, lo que implica un constante flujo migratorio campo-ciudad. Esta dinámica, que va acompañada también del uso de agro-tóxicos a escala masiva, es la que explica, por un lado, el hecho de que un $82 \%$ de la población indígena Argentina resida en ámbitos urbanos. También explica los límites para la regularización de los asentamientos de los pueblos originarios, cuyos derechos están garantizados constitucionalmente.

En este contexto, las comunidades indígenas rurales intentan resistir a semejante dinámica expulsiva en condiciones desiguales, reclamando los territorios que son, "su almacén primitivo de víveres" y al mismo tiempo garantía de su supervivencia como pueblos originarios. Es por ello que la territorialidad es parte constitutiva de las principales demandas de las comunidades y pueblos indígenas rurales. Al mismo tiempo dicha territorialidad se configura en muchos casos como ámbito de reproducción de sus vidas en tanto fuerza de trabajo estacional, que puede ser empleada a un precio por debajo del salario mínimo rural vigente.

A la invisibilización estadística de los pueblos originarios argentinos se le agrega también el desinterés por los estudios sobre su dinámica productiva y reproductiva, lo que impide la generación de políticas de intervención eficaces desde los criterios establecidos en la reforma constitucional y otras normativas vigentes.

\section{Bibliografía}

ADMINISTRACIÓN DE PARQUES NACIONALES. Programa Pobladores Y Comunidades (2007) Proyecto "Desarrollo de Capacidades Nacionales para el Fortalecimiento del Sistema Nacional de Áreas Protegidas". Anexo: Plan de Pueblos Indígenas. Buenos Aires.

BALAZOTE, A. (1994). Impacto social en la reserva mapuche de Pilquiniyeu del Limay. Tesis de Doctorado - Facultad de Filosofía y Letras - Universidad de Buenos Aires.

BARTOLOMÉ, M. A. (2003). Los pobladores del "desierto". Genocidio, etnocidio y etnogénesis en la Argentina. En Cuadernos de Antropología Social $N^{o} 17$. Buenos Aires

BARTH, F. (comp.) (1976). Los grupos étnicos y sus fronteras. Fondo de Cultura Económica, México.

BECHIS, M. (1992). Instrumentos para el estudio de las relaciones interétnicas en el periodo formativo y consolidación de los estados nacionales. En Hidalgo, C y Tamagno L (comp.). CEAL, Buenos Aires. 
BONFIL BATALlA, G. (1992). Identidad y Pluralismo Cultural en América Latina. Fondo Editorial del CEHASS, Buenos Aires.

BONFIL BATALLA, G. (1991). Pensar nuestra cultura. Alianza Editorial, México.

CARDOSO DE OLIVEIRA, R. (1992). Etnicidad y estructura social, CIESAS, Colección Miguel Othón de Mendizábal, México, D.F.

CEDCAPI-EDUCACIÓN (2007) Participación e Innovación en la Educación Superior. Programa Nacional de Voluntariado Universitario. SPU, Ministerio de Educación, "Producción de materiales didácticos y de lectura en lenguas aborígenes", pp. 123- 128. Buenos Aires.

COMAS D'ARGEMIR, D. (1998) Antropología Económica. Cap. III. Ed. Ariel Antropología, Barcelona.

DÍAZ POLANCO, H. (1995). Etnia y Nación en América Latina. Consejo Nacional para la Cultura y las Artes, México.

FLACSO. Informe de López Arceo. Resumen en Diario Página 12 del 5 de septiembre de 2009, Pág. 5 Sección Economía. Buenos Aires.

FRANCO PELLOTIER V. M. (1992) Grupo doméstico y reproducción social. Ediciones de la Casa Chata. México.

GOLLUSCIO, L. (2002). Los pueblos indigenas que viven en Argentina. Actualización del año 2002. 1a ed. Secretaría Agricultura, Ganadería, Pesca y Alimentos. Documentos de capacitación; 5. Buenos Aires.

GORDILLO G. (1995) La subordinación y sus mediaciones. Dinámica cazadorarecolectora, relaciones de producción, capital comercial y Estado entre los Toba del oeste de Formosa. En H. Trinchero (comp.) Economía doméstica y capital. Ed. Biblos, Buenos Aires.

GRANOVETTER, M. (1992) The nature of economic relations. En S. Ortiz y S. Lees Understanding Economic Process. Monographs in Economic Anthropology. Society for Economic Anthropology. University Press of America, Boston.

HARRIS, O. (1987) Economía Étnica. Hisbol, La Paz.

HIDALGO, C. Prologo. (1992). En HIDALGO C. Y TAMAGNO L. (comps.) (1992). Etnicidad y Identidad, Centro Editor de América Latina, Buenos Aires.

INDEC. (2004-2005). Encuesta Complementaria de Pueblos Indígenas (ECPI) 20042005. Complementaria del Censo Nacional de Población, Hogares y Viviendas 2001. En: www.indec.gov.ar/

ITURRALDE, D. (1995). Naciones Indígenas y Estados Nacionales en América Latina hacia el año 2000. En: DÍAZ POLANCO, H. (comp.) Etnia y Nación en América Latina. Consejo Nacional para la Cultura y las Artes, México.

LEGUIZAMÓN, J. M.; VALVERDE, S. y MOREY, E. (2007) Diagnóstico preliminar proyectos del programa social agropecuario (PSA) en relación a los pueblos originarios. Ministerio de economía y producción secretaría de agricultura, ganadería, pesca y alimentos. Informe, mimeo. Buenos Aires

MEILLASSOUX, C. (1977) Mujeres, graneros y capitales. Editorial Siglo XXI. México

NEIMAN Y OTROS (2006) Los asalariados del campo en la Argentina. Diagnóstico y políticas. SAGPyA. Serie Estudios e Investigaciones $N^{\circ}$ 9. Buenos Aires.

POUILLON, F. (1976) L'anthropologie economique: courants et problemes, Francois Maspero. Paris.

RADOVICH, J. C. Y BALAZOTE, A. (1992). La problemática indígena, CEDAL, Buenos Aires.

RADOVICH, J. C. (1992). Política Indígena y Movimientos Étnicos: el caso Mapuche. En: Cuadernos de Antropología Vol. 4, Universidad Nacional de Luján.

ROFMAN, A (2004) "El modelo económico-social de la década de los noventa y su expresión regional”, en: Boyer y Neffa: La economía Argentina y su crisis (1976-01), ceil-pietta. Buenos Aires.

SANCHEZ, J. O. (1987) Modelos procesuales en antropología ecológica y económica. En Agricultura y Sociedad $N^{\circ} 40$. 
SCHIAVONI. G. (1995) Colonos y Ocupantes. Caps. II, III y IV. Editorial Universitaria. Universidad Nacional de Misiones. Posadas.

SLUTZKY D. (2008). Situaciones problemáticas de tenencia de la tierra en Argentina. Ministerio de economía y producción Secretaría de Agricultura, Ganadería, Pesca y Alimentos Dirección de Desarrollo Agropecuario, PROINDER. Serie estudios e investigaciones $n^{\circ} 14$ Buenos Aires.

SOVERNA, S.; TSAKOUMAGKOS, P.\& PAZ, R. (2008). Revisando la definición de agricultura familiar - 1a ED. - Buenos Aires: Secretaría Agricultura, Ganadería, Pesca y Alimentos, E-Book. Serie Documentos de Capacitación; 7.

TRINCHERO, H. (2007) Aromas de lo exótico (Retorno del objeto). Para una crítica del objeto antropológico y sus modos de reproducción. Ed. Sb, Buenos Aires.

(2000). Los Dominios del Demonio. EUDEBA, Buenos Aires.

(1995). Producción doméstica y capital. Estudios desde la Antropología

Económica. Biblos, Buenos Aires

(1992). Antropología Económica. Introducción y conceptos

fundamentales. Vols. 1 y 2. CEAL, Buenos Aires.

y otros (1992). Capitalismo y grupos indígenas en el Chaco centro occidental (Salta y Formosa) Vol. 1 y 2. CEAL, Buenos Aires.

TRINCHERO, H. Y BALAZOTE, A. (2000) Etnicidades y territorios en redefinición. Una perspectiva histórica y Antropológica. Facultad de Filosofía y Humanidades. Universidad Nacional de Córdoba, Córdoba.

VAN DAM, C. (2008) Tierra, Territorio y Derechos de los Pueblos Indígenas, campesinos y pequeños productores de Salta. Ministerio de economía y producción Secretaría de Agricultura, Ganadería, Pesca y Alimentos Dirección de Desarrollo Agropecuario, PROINDER. Serie DOCUMENTOS DE CAPACITACIÓN nº 2, Buenos Aires.

VÁZQUEZ, H. (2000) Procesos identitarios y Exclusión Sociocultural. La cuestión indigena en la Argentina. Ed. Biblos, Buenos Aires. 